\title{
A STEP BY STEP APPROACH TOWARDS PLANNING A SMART SUSTAINABLE CITY USING A STRATEGIC PLAN
}

\begin{tabular}{|c|c|}
\hline SEKHAR KONDEPUDI & ANUPAMA KONDEPUDI \\
Associate Professor, & Principal, \\
Smart Buildings and Smart Cities, & Kondepudi Strategies, \\
National University of Singapore & Singapore / San Jose, USA \\
\hline
\end{tabular}

\section{ABSTRACT}

In this paper, the authors propose a Step by Step Approach towards Planning a Smart Sustainable City. Utilizing a strategic planning approach for developing smart cities by governments and stakeholders helps in the completion and implementation of the smart city project. Along with operational plans, master plans for urban planning and digital/ICT infrastructure are presented. Smart Infrastructure solutions such as "Smart" Transport, Energy, Water, Waste, Security, Education and Healthcare are discussed.

A citizen centric approach to meet a smart city resident needs will enhance the Smart City citizens' quality of life. Prioritizing the needs, solving the challenges and addressing financial constraints by Public Private Partnership models are recommended. A successful smart city operation is accomplished by a step by step approach using different technological solutions available today.

\section{Introduction}

A Smart City should be implemented for the citizens' considering their challenges and using technology resolve these challenges. To maximize the benefits different ICT technology based solutions may be mapped to meet citizen needs. A clear understanding of the challenges will help analyze, implement and prioritize to design smart solutions.

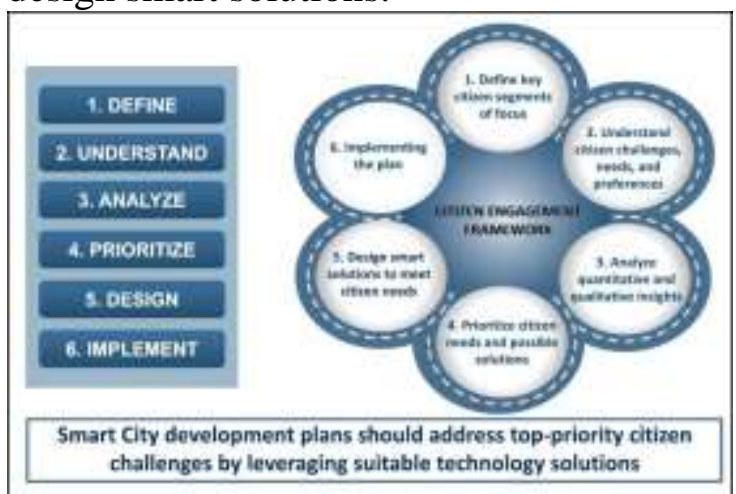

\section{Figure 1: Smart City citizen engagement framework}

Source: Frost \& Sullivan

Key aspects of developing a smart city strategic plan are to have a vision and mission. Step by step, the guiding principles, framework have to be discussed by the stakeholders. Based on the ecosystem and leveraging role of ICT, smart infrastructure solutions have to be implemented using innovative financing

\section{strategies.}

\section{Definitions}

Among the many definitions in the literature for smart cities is a definition developed by authors of a Focus Group on Smart Sustainable Cities (FG-SSC) of the International Telecommunications Union (ITU):

"A smart sustainable city is an innovative city that uses information and communication technologies (ICTs) and other means to improve quality of life, efficiency of urban operation and services, and competitiveness, while ensuring that it meets the needs of present and future generations with respect to economic, social, environmental as well as cultural aspects.. (ITU, UNECE)",

\section{Smart City Strategic Plan}

A Smart City Strategic plan is essential and critical for any Smart City Planning and Development. It is a high level planning tool for the long term to guide stakeholders and governments achieve their objectives by establishing an appropriate mission and vision. Important infrastructure elements that work together with the Smart City framework are described so that a realistic approach towards implementation is 
developed. Along with a smart governance process and the recommended next steps. The Smart City Strategic Plan has to be constantly upgraded based on the feedback, inputs and progress.

\section{Strategic Plan is NOT}

A Strategic Plan is not an advocacy document. It is also not for recommendations for Specific technologies or vendors or Smart City Masterplan or implementation/master plans.

Develop a Vision and Mission for Your Smart City

No two cities are alike. Therefore, the Vision and Mission for any smart city will be very specific and unique to that particular city. The context, situation, conditions, needs, aspirations and goals for a city play a major role in developing the vision and mission and must be considered very strongly. The vision for a Smart City will need to be based on local conditions but will still need to be aligned to the city and national plan.

Vision

An example, vision statement is: "A Smart City that leverages the foundations of good Urban Planning, ICT Technologies, Open Data, Transparent Governance, will create a vibrant, people-centric, connected and economically prosperous international city”.

\section{Mission}

Smart City goals and the direction to follow to achieve these goals are established in a mission statement.

An example mission statement is: " $A$ technologically superior place to live and work acting as an economic hub, integrated with ICT technologies for lifestyle management of citizens, business, research and development. Encourages competitive growth and innovation with environmental sustainability and conservation of resources while simultaneously fostering cultural and social interactions to celebrate heritage".

\section{Strategic Alignment with Vision}

Smart Strategic Objectives for Smart City include Smart Living, Smart Governance, Smart Mobility, Smart Environment and Smart Economy. A Smart City will provide its citizens a better quality of life with improved city services and facilities like housing and utilities for Smart Living. Smart Governance of a smart city is via stakeholder involvement in the policy making and implementation, leveraging technology to facilitate the process leading to better transparency and accountability. Smart Mobility / Transportation will reduce congestion and foster faster, greener and cheaper transportation options while being environmentally sustainable. Data collected about mobility patterns will help optimize traffic conditions in a holistic manner. Smart Environment will make a smart city an eco-efficient city that effectively manages and uses the growth to improve and protect the environment using optimal water and natural resources. The key parts of a smart economy leading to greater investments are economic development, higher employment and a knowledge economy.

\section{Develop Guiding Principles}

Guiding principles to be followed by a Smart City government and other key stakeholders in planning the design and implementation of the Smart city are livability, management of services, mobility and improved connectivity. Each smart initiative has to be applied to these guiding principles to ensure that the mission and vision of a smart city are being met.

A livable vibrant city makes it better for 
citizens by improving delivery and management of Services resulting in economic growth and employment opportunities. Proving to be a long-term sustainable solution. Transport, people movement and digital connectivity may be improved with improved connectivity. Enhancing individual development, community engagement and connectedness within the different parts of the city. Bringing awareness of culture and heritage diversity, and sporting interests within the city. For the betterment of citizens, open government and open data can be leveraged.

\section{Establish a Smart City Framework}

Understanding how the different facets of a smart city relate to one another can be accomplished by Frameworks. Helps in visualization of services and infrastructure. Frameworks can be used to plan, develop, operate and map the different aspects of a smart city clearly. Figure 2 is a sample generic framework that can be used for the establishment of a smart city and customized as necessary.

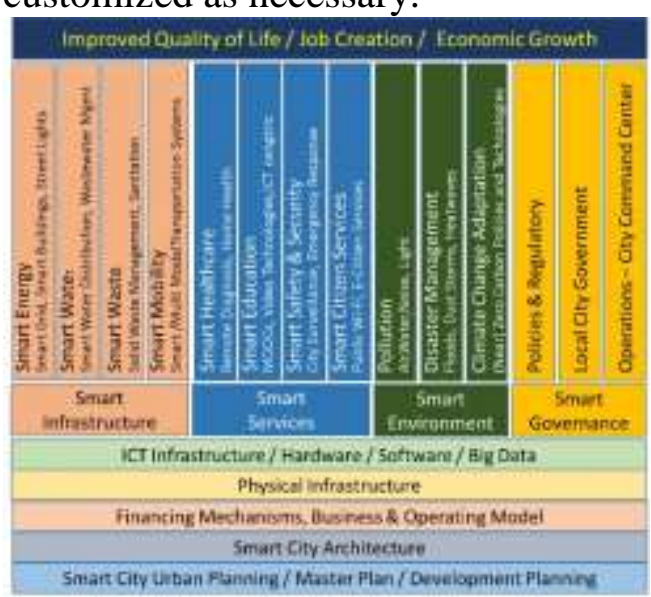

Figure 2 Framework for Sample Smart City

Graphic used with permission of Sekhar \& Anu KONDEPUDI

Various verticals of the framework include- smart infrastructure, services, environment and governance systems required for a smart city. Smart infrastructure provides robust cost effective smart city infrastructure requirements such as energy, water, waste, mobility and real estate. Citizen services Infrastructure required by the city include healthcare, education, safety, cultural requirements and smart social infrastructure to ensure intelligent and better connected infrastructure for various social needs. Sustainable and environment-friendly city to deal with climate change, pollution, disaster management and any other city specific issues. An urban local body with Good governance mechanisms with policies and regulations to ensure proper functioning of all systems and processes.

Identify and Engage with Key Stakeholders Local city administration, Municipalities or City Council, National and regional governments, City services companies, Utility providers, ICT Companies, NGOs, International, Regional and Multilateral Organizations, Industry associations Academia, research organizations and specialized bodies, Citizens and citizen organizations, Urban Planners and Standardization bodies are Smart City stakeholders. Any entity, institution or individual, with an interest in smart cities or can significantly influence or be influenced by smart city deployment is a smart city key stakeholder.

\section{Smart City Ecosystem}

A smart city ecosystem will have 4 major types of players namely Syatem Integrators, Network Providers, Product and Device vendors and Managed Service Providers. System Integrators bring together Various Actors \& Stakeholders via "pre-packaged" platforms to create a unified, holistic end to end solution for

Smart Cities. Network Providers for 
Data Communication, Collaboration, Secure Enterprise Grade Systems and Solutions leveraging on Network and M2M capabilities. Product and Device Vendors of Actual Devices IoT (Internet of Things) Players example Sensors, Smart Meters, Building Automation Systems, Associated Software Solutions. Managed Service Providers for Monitoring, Collecting, Analyzing and Operating the City 24/7. They run the city via Private or Public or Hybrid (PPP) partnerships. These types of players will have a highly matrixed relationship with each other forming a holistic $360^{\circ}$ relationship.

\section{Embrace the Role of ICT in Smart City}

\section{Introduction}

Information \& Communication Technology (ICT) - helps cities to become more sustainable with better communication flow allowing citizens to make better decisions by increasing participation. This also helps in providing a feedback system between local communities and its citizens.

A Smart City will need to create a state-ofthe-art physical infrastructure related to electricity, water, gas, cooling, roads and telecommunications. City based development uses ranging from residential, commercial to offices and industrial needs are to be considered. Connectivity is needed to the transport hubs. These hubs are established to leverage the flow of goods and services. The city has to have the infrastructure to make it more amenable for living and hence planning has to be coordinated.

\section{ICT Planning Essentials}

ICT planning is an essential part of the smart city planning process. Deployment of
Broadband Networks, Use of Smart Devices and Agents, Developing Smart Urban Spaces, Developing Web-based Applications and e-Services and Opening up Government Data are the 5 key steps to a smart city.

\section{Deployment of Broadband Networks}

Wired or wireless High speed broadband networks -are needed for the implementation of a smart ICT plan for a city and to all citizens. Use of sensors to develop intelligent solutions will be possible with highest broadband connectivity and bandwidth as networks form the backbone of digital applications.

\section{Use of Smart Devices and Agents}

Alerts and information processing by real time data management can be used by the city management. These systems and smart devices, sensors and actuators with wireless connectivity helps the city make educated informed decisions.

\section{Developing Smart Urban Spaces}

Wi-Fi hot spots and information desks may be used to deliver sustainable and efficient services. City Wide Wi-Fi, Electric Car Charging Infrastructure, smart transport systems, Smart Meters in buildings, and infrastructures are a few example services providing internet on the move.

\section{Developing Web-based Applications and e-Services}

Sensors can be leveraged to provide a seamless experience to the residents of the city for providing e-services. Smart city eservices are energy and transport services, safety and security services, education and health services are critical to a city. For example, traffic management and alerts are made possible by Intelligent Transport Systems (ITS). 


\section{Opening up Government Data}

Opening up government data can lead to societal benefits. The effective use of government data can help in the smart evolution of cities, more socially inclusive service delivery and creating a national competitive advantage for the stimulation of the economy. A good example is the Singapore Government data portal: http://data.gov.sg acting as a platform for new product development using public data by individuals and organizations.

\section{Digital (ICT) Infrastructure}

A digital ICT platform may be used to create a knowledge and information network to aggregate all the data collected from various city systems and for data analysis. This real time data analysis will give a depth on how the various systems are working together. Such as energy or water consumption, traffic patterns of automobile or citizens, pollution levels or waste management conditions. Three essential tasks to develop an ICT \& Data infrastructure in a smart city are Mobile broadband and Broadband Connectivity, Internet of Things and Smart Sensors and Devices use, and Data Capabilities. An affordable reliable broadband network to implement smart city technologies needed are high speed network access points, fiberoptic lines, broadband wireless, sensors, and datacenters. Including services like Ultra-fast internet, IP telephony, viewing movies online, data transmission, and cloud computing. For enhanced high speed smart phone capabilities a robust fiber optic network and a next-generation wireless network (4G / 5G / LTE) needs to be deployed to the entire smart city for seamless connectivity. Supporting future data centers hosting Google, YouTube, Facebook, Microsoft, Akamai, etc.

\section{Study and Implement Smart Infrastructure Solutions}

IBM states that "A smart city is one that makes optimal use of all the interconnected information available today to better understand and control its operations and optimize the use of limited resources". The two digital phenomena forming a key part of the digital (ICT) infrastructure needed for smart infrastructure in a city are Internet of things (IoT) and Big Data. Smart buildings, smart transport, smart power, smart health, smart water and smart waste are examples of sensors coupled with data and network connectivity to form a Figure 3 "smart infrastructure".

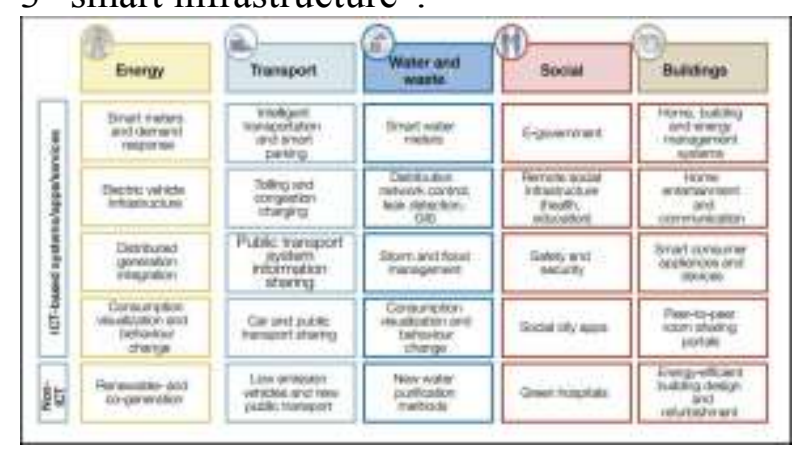

Figure 3: Smart Infrastructures using ICT

Expanding Participation and Boosting Growth: The Infrastructure Needs of the Digital Economy, World Economic Forum Report, March 2015

Each infrastructure component of a smart system works with the other in a building to make it a "smart" building and work together based on an ICT system. An example smart building will be using energy, water and generates waste and maintained via an ICT based system or application or services. Efficiency is enhanced because each component is working together than in silos. ICT combined with physical infrastructure represents "smart infrastructure" as shown in the "Smart Infrastructure Examples" table below: 
Smart Infrastructure Examples

\begin{tabular}{|c|c|c|}
\hline Need / Challenge & Example Solution & Description \\
\hline \multirow[t]{2}{*}{$\begin{array}{l}\text { Energy / Utility } \\
\text { Infrastructure } \\
\text { Improvement }\end{array}$} & Smart Meters & $\begin{array}{l}\text { Metering of power, water and gas that can } \\
\text { provide real time measurement of energy } \\
\text { consumption }\end{array}$ \\
\hline & Renewable energy & $\begin{array}{l}\text { Generation of power including solar, hydro, } \\
\text { thermal and fuel cell technology. }\end{array}$ \\
\hline \multirow{2}{*}{$\begin{array}{l}\text { Provision of widespread } \\
\text { and affordable broadband }\end{array}$} & High Speed Internet & Fiber to the Home. \\
\hline & $\begin{array}{l}\text { Public Wi-Fi \& } \\
\text { High } \\
\text { Speed Internet }\end{array}$ & Mobile Internet access in public locations. \\
\hline \multirow[t]{5}{*}{$\begin{array}{l}\text { Development of urban } \\
\text { Infrastructure - Cars / } \\
\text { Parking / Buildings /Streets }\end{array}$} & $\begin{array}{l}\text { Smart LED street } \\
\text { lighting }\end{array}$ & $\begin{array}{l}\text { Light sensors and communication devices to } \\
\text { allow lights to communicate with other nearby } \\
\text { lights and to be controlled at a city level. }\end{array}$ \\
\hline & Smart buildings & $\begin{array}{l}\text { Array of sensors and technologies that } \\
\text { improve, safety, security, energy efficiency } \\
\text { and } \\
\text { usability. }\end{array}$ \\
\hline & $\begin{array}{l}\text { Electric Vehicles } \\
\text { \& Charging }\end{array}$ & $\begin{array}{l}\text { Cars which operate on electricity / batteries } \\
\text { with appropriate infrastructure for charging } \\
\text { stations throughout the metropolis }\end{array}$ \\
\hline & Smart Parking & Car parks and street parking locations. \\
\hline & \begin{tabular}{ll|} 
Smart & Traffic \\
Lights &
\end{tabular} & $\begin{array}{l}\text { Automated sensing and management of } \\
\text { traffic. }\end{array}$ \\
\hline $\begin{array}{l}\text { Improvement of } \\
\text { environmental conditions } \\
\text { such as pollution }\end{array}$ & $\begin{array}{l}\text { Environmental } \\
\text { Sensors }\end{array}$ & $\begin{array}{l}\text { Data collection about the condition of air, } \\
\text { water and soil. }\end{array}$ \\
\hline $\begin{array}{l}\text { Focus on public security } \\
\text { and safety }\end{array}$ & Video Security & $\begin{array}{l}\text { Public safety, crowd management and people } \\
\text { counting. }\end{array}$ \\
\hline $\begin{array}{l}\text { Increasing efficiency } \\
\text { (reducing costs), }\end{array}$ & & Monitoring and management of a range of \\
\hline $\begin{array}{l}\text { Increasing } \\
\text { effectiveness (increasing } \\
\text { productivity) }\end{array}$ & Operations Centre & $\begin{array}{l}\text { government, transport, environmental and } \\
\text { emergency services. }\end{array}$ \\
\hline $\begin{array}{l}\text { Provision of new services } \\
\text { such as health and } \\
\text { education }\end{array}$ & Remote Healthcare & $\begin{array}{l}\text { Products and services for remote access to } \\
\text { health services. }\end{array}$ \\
\hline
\end{tabular}

Intelligent Mobility and Transportation

Movement of people (and goods) efficiently, safely, economically can be defined as Intelligent Mobility and Transportation. When physical infrastructure is unable to keep pace with the population and economic growth it leads to traffic congestion. This is a pressing issue in both developed and developing worlds where all modes of transport are used in a city. Including walking, cycling, public and private 
motorized transport (2, 3, or 4 wheeled) and mass rapid transit. Each of these modes have to be analyzed to use the infrastructure better and relieve traffic congestion.

\section{Smart Energy Management}

Meeting energy needs in an environmentally sustainable manner at a low cost is Smart-Energy $^{8}$. New smart energy technologies such as Smart grid meters, Micro grids, Smart Street lighting, Renewable energy sources, Solar energy, Advanced distribution management are to be used in smart cities.

\section{Smart Water}

Use of ICTs of a smart water system helps save water, reduce cost, increase reliability and transparency of water distribution. Smart water management system ICT not only helps save water but also improve water security and quality by reducing leaks. Real time network updates on the water pipe status can reduce water bills and conserve water by analyzing the water pressure and flow data.

\section{Security \& Surveillance}

Security and surveillance of smart cities can be achieved effectively and efficiently using information technologies. It can be automated and remotely checked in real time from anywhere in the city or anywhere in the world. Integrated with the command and control systems of police and emergency services for the fastest and most appropriate response.

\section{Smart Buildings}

Different physical systems present in a building (such as Building Automation System (BAS) - HVAC \& Energy Management, Lighting Control System, Fire \& Life Safety Control Systems, Parking Guidance and Management Systems) are integrated in an intelligent manner to form a smart building. All the different systems in a building act together in an optimized and efficient manner to make it reliable, cost effective, and sustainable. The goal is for enhancing productivity and performance and to provide comfort for the well-being of residents. Up to date information provided by these smart building management systems can improve building energy efficiency. Wastage can be reduced and it is estimated that implementing smart building solutions could result in reduction of water usage by $30 \%$, energy usage by 40 percent, and building maintenance costs by $10-30$ percent. It has been found that energy use in existing buildings can be reduced by up to $50 \%$ through simple retrofit programmes.

\section{Smart Education}

Smart education objectives may be set with smart digital education platforms for smart cities and across extended geographies. Through Digital education thereby a wider audience will gain access to classrooms via technology. Perhaps even across different socioeconomic backgrounds and ages using online programs. Subsequently helping people with job readiness skills with a range of technology classes.

\section{Smart Healthcare}

'Smart Healthcare' provides healthcare by monitoring the health conditions of citizens using intelligent and networked technologies. Prevention, healthy living and wellness management being the primary focus. Ensuring the availability of appropriate health care and resources at the right time for both in-patients and outpatients. Smart healthcare systems are being used in both developed and developing nations. A few examples of smart health are patient monitoring remotely by the use of online digital records, online appointments, treatment or tele-assistance, electronic health management system and or patient 
monitoring systems.

\section{E-Governance \& Citizen Services}

By ensuring all government services are easily available to all citizens and having a robust e-governance, a smart city can enhance the quality of life its city residents. Having a set of efficient, transparent and reliable citizen services an integrated information infrastructure may be accessed by all residents. Such services include online government information portals, municipal services, disaster management, GIS maps, residential parking permits, permit applications and payments, address change or updates and various land use, planning or property tax certificates. Citizens will be able to participate in the governance using Smart city apps, SMS text services, report problems via a complaint hotline or get weather updates.

\section{Smart Waste Management}

Smart waste management systems help create closed loop economies by converting waste into a resource. They also help reduce wastage, segregate the waste and develop methods for proper usage of waste. Efficiency of waste management trucks for pick up can be improved as often trucks are sent out to collect waste but the bins are not full or bins are overflowing. Helping reduce truck fuel costs. Sensors, internet connectivity and the Internet of Things (IoT) help monitor and mitigate waste pickup and recycling costs by continuously monitoring waste collection.

\section{Smart Environment}

Green buildings, green energy, green urban planning, pollution and other ecological aspects help establish a Smart Environment and create a reduced low carbon environmental footprint. Use of green data centers, air quality sensing, noise maps and meteorological station network updates helps monitor the environment efficiently.

\section{Need for Holistic Approach}

Water, waste, buildings are a few infrastructure elements of a city which are a part of system of systems connected by a communications data network or communicating between themselves. Internet of Things (IoT) are these different infrastructure verticals forming a "system of systems" - translating into a "network of networks"- commonly known as the ICTs. They form the backbone for communication acting as a 'glue' between various forms of physical infrastructure (Figure 4). Connecting different aspects of everyday living to public infrastructures, such as utilities, mobility and water creating alerts about specific conditions such as flooding or traffic congestion.

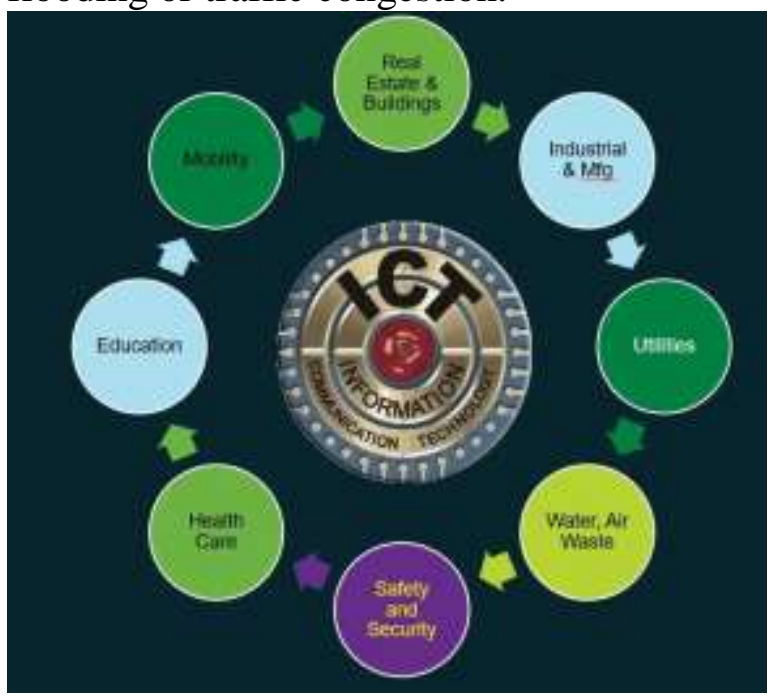

Figure 4: City Infrastructure elements with ICT focus

\section{Establish Governance and a Project Structure}

\section{Smart Governance}

Smart Governance involves managing a city government with efficiency, increased community involvement, leadership and improved innovation using technology. Citizens are connected to the government 
with the help of technology for planning, decision making for improved public services. This is accomplished by a social network platform enabling a dialogue or becoming a platform for information gathering. Smooth functioning of a Smart City is possible by Smart Governance. Public trust and participation of all stakeholders helps a smart city to succeed.

Good governance practices are Encourage Business innovation, Engage with Citizens Early, Good and Proactive Political Leadership, Holistic Organization and Civic Engagement, Encourage social innovation, Establish Sustainable Communities Through Real-time Information and Resource Sharing and Encourage Community Planning and CoCreation. This can be achieved by having Visionary Leadership \& Political Will, Good Understanding of Potential Pitfalls, Translating Vision into a Practical View, Make Business / Economic Sense, Incentivize Innovation, Good Urban Planning - Design the City, Break the City Down into Small Chunks and Educate the Citizens.

Consider Financial Aspects and PublicPrivate Partnerships (PPP)

Need for Innovative Financial Mechanisms Smart cities are very expensive to implement and also operate. The order of the day in a smart city includes new citizen services, different traffic modes, utility and city (municipal) operations. Ability to meet all of these goals is difficult as it is, but adding to the basket of concerns is the additional financial constraints that delay, curtail, or even render ineffective, the ability for governments to improve the quality of life in their communities. There is a need for large amounts of capital, upfront investments for infrastructure building across the different vertical sectors but there is a huge need for effective budgetary planning and. Without proper and focused planning, the budgets will fail as funds will not be disbursed effectively. There is a need to invest across all the different verticals or sectors in a smart city, or else there will be a serious imbalance in the city (Figure 5).

As with most cities, it is nearly impossible and implausible that the government single handedly bear the burden of financing the infrastructure and other costs associated with smart cities. Private sector funds are essential for the success of a smart city. This not only mitigates the risk and ensures that the implementation of the city will be realistic and market driven. Such a hybrid public and private approach implies the need for creative financing and business models to reduce the investment risk through policies, tax and regulatory instruments. The uncertainty related to these policy and related instruments remain a key unknown and area of uncertainty for the private sector and investor community.

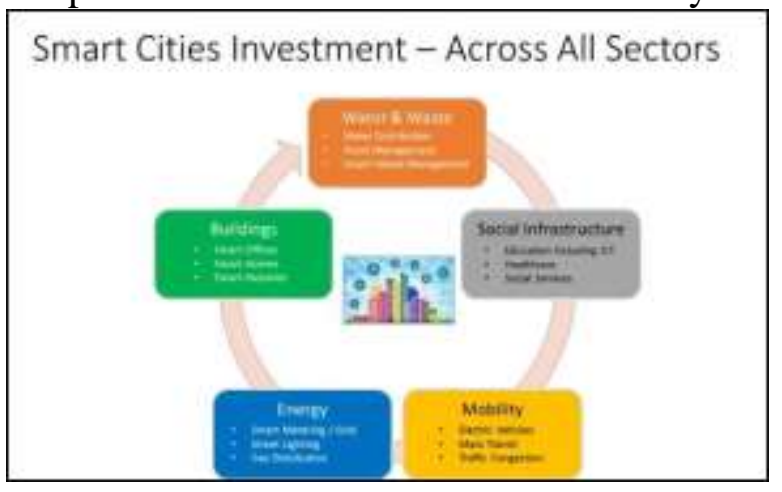

Figure 5: Investment Across All Sectors

\section{Innovative Financing}

A smart city needs to consider different and new forms of business and financial models which are both innovative yet attractive. These new models must be based on a very crisp, clear budget and plan which is "SMART - Specific, Measureable, Achievable, Realistic and Timely". The financial plans and models must have a roadmap, a clear priority on hat to spend on, 
have a pragmatic analysis model, and a legally binding recovery mechanism.

Public- Private Partnerships (PPP)

PPPs can be a viable financial and legal vehicle to deliver smart city infrastructure and services in an efficient and cost effective manner. A variety of private sector verticals such as ICT, energy management and transportation can potentially provide co-funding and in the process, help address environmental, social and health challenges. There are clear benefits which can be derived from aligning government and private sector industries, in terms of technology, assets, and capital. Partnerships between governments, organizations and industries can be leveraged along with skills and experience of the private sector leveraged to shorten delivery timelines, a sharing of risks and an better value for money (or return on investment) for the project.

Special Purpose investment and corporate vehicles (SPVs) help in implementing essential infrastructure components through major private sector participation. Some examples of SPVs (infrastructure companies) might include the following: ICT services, District Cooling Systems, Special Economic Zones (SEZ), Power Companies, Water Infrastructure and Waste Management Services.

\section{PPP Operating Models}

Public and private sector partnerships (PPP) help implement smart city projects. One of the key characteristics of a PPP is that there is a need for a reasonable return on investment (ROI) especially for the Private sector. If this ROI is not achievable, the private sector will typically not invest. Successful examples of PPPs include highways and transportation. There is a strong dependency on the key stakeholders i.e. the investors, companies, the ecosystem, the National or State government, the local government, governance and also financing. There are three primary operating models for a Smart City PPPs : (1) Build Own Operate (BOO), (2) Build Operate Transfer (BOT) and (3) Build Operate Manage (BOM). The city will need to resolve which models are applicable and make the most economic sense - or perhaps a hybrid model.

\section{Build Own Operate (BOO)}

In this model, the city itself drives the entire process and is responsible for building the city infrastructure and delivering smart city services. The BOO model is generally used when a city or government has sufficient financial wherewithal to develop the smart city.

\section{Build Operate Transfer (BOT)}

In contrast with the BOO model, in the BOT model, the city appoints a trusted third party partner (private sector) to build the city infrastructure and provide smart city services for a pre-stipulated time period. The BOT model is generally used when a city or government has funding constraints.

\section{Build Operate Manage (BOM)}

The BOM model is the most popular PPP instrument. The city chooses (normally via an extensive and open, transparent tendering process) a trusted third party partner to develop the city infrastructure and services. This model is normally used when private companies are involved in building, operating and managing smart infrastructure.

\section{In Summary}

A Smart City Strategic Plan is a tool for the governments and stakeholders to achieve their vision and mission using a smart city framework. The governance process, initiatives and smart city solutions have been recommended for laying a foundation for urban planning. An ICT Technology Plan and a financial plan are suggested for implementation and operation of Smart City project. Smart city definitions have been discussed so that the applicable 
definitions will be helpful in developing a strategic plan in the context of the specifics for a given city. Drivers such as usage of existing submarine cables or network fiber, railway lines, airports, ports, economic competition nationally and internationally have been mentioned.

Having a smart city will improve the livability of a city but challenges such as environmental, social, cultural, technological and medical services have to be addressed. Consequently, economic stability and GDP can be improved with better employment opportunities. Simultaneously improving the environment and sustainability of the city.

Strategic objectives of a Smart City are Smart Governance, Smart Living, Smart People, Smart Economy, Smart Environment and Smart Mobility. Utilities, water supply and affordable housing provision will provide citizens a better quality of life. Strong diverse communities that can live well with better educational facilities and community participation and governance. Transport congestion will be reduced with cheaper and sustainable transportation. Including mass transit systems. Water and energy resources will be optimally used for ecologically sustainable development as it will be an eco-efficient city with improved resource management. Economic growth will help build the city by providing a good labor pool. Stakeholders will be involved in policy making and implementation so that municipal administration efficiency will improve. Citizen centric aspects have to be included in the smart city development plans to address citizens' priorities by using technology.

\section{Bibliography / Reading}

[1] 10 steps to building a smart city, Tamsin Rutter, The Guardian 6 August
2015 ,

http://www.theguardian.com/publicleaders-network/2015/aug/06/10steps-to-building-a-smart-city. 100 Smart cities in India Facilitating implementation, For Private circulation amongst delegates of

[2] "100 Smart Cities: Need for Innovation and Integrated Approach" workshop on 10th February 2015 www.deloitte.com/in

[3] An Overview of key performance indicators in Smart Sustainable cities, ITU FG-SSC, Technical Report. ITU 2014

[4] An Overview of Smart Sustainable cities and the role of information and communication technologies, ITU FGSSC, Technical Report. ITU 2014

[5] An Overview of Smart Sustainable cities infrastructure, ITU FG-SSC, Technical Report. ITU 2015

[6] Anonymization infrastructure and open data in Smart Sustainable cities, ITU FG-SSC, Technical Report. ITU 2015

[7] Cyber security, data protection and cyber resilience in Smart Sustainable Cities, ITU FG-SSC, Technical Report. ITU 2015

[8] Delivering Smartcities, GOVERNING CITIES IN THE DIGITAL AGE, Stephen Hilton, Spend Network, 2014 http://www.ucl.ac.uk/steapp/docs/deli vering-the-smart-city .

[9] Electromagnetic field considerations in Smart Sustainable Cities, ITU FGSSC, Technical Report. ITU 2014

[10] Five ICT Essentials for Smart Cities, A Whitepaper for Business, Escher Group, $\quad 30 \quad$ June 2015. www.eschergroup.com/publications/fi ve-ict-essentials-for-smart-cities.cfm

[11] HABITAT III ISSUE PAPERS , 21 SMART CITIES , UNITED NATIONS, UN Habitat, New York, 31 
May 2015. http://unhabitat.org/wpcontent/uploads/2015/04/Habitat-IIIIssue-Paper-21_Smart-Cities.pdf

[12] How to build a city from scratch: the handy step-by-step DIY guide - Stuart Jeffrioes, 30 June 2015, The Guardian. http://www.theguardian.com/cities/20 15/jun/30/how-build-city -step-bystep-diy-guide

[13] India: Surging to a smarter future, PWC, (210`15) https://www.pwc.in/assets/pdfs/public ations/2015/india-surging-to-asmarter-future.pdf

[14] Information and communication technologies for climate change, Smart Sustainable cities, ITU FG-SSC, Technical Report. ITU 2015

[15] Integrated management of Smart Sustainable cities, ITU FG-SSC, Technical Report. ITU 2015

[16] Intelligent sustainable buildings for Smart Sustainable cities, ITU FG-SSC, Technical Report. ITU 2015

[17] Key performance indicators definitions for Smart Sustainable cities, ITU FG-SSC, Technical Report. ITU 2015

[18] Key performance indicators related to the role of information and communication technologies in Smart Sustainable cities, ITU FG-SSC, Technical Report. ITU 2015

[19] Key performance indicators related to the sustainability impacts of information and communication technology in Smart Sustainable cities, ITU FG-SSC, Technical Report. ITU 2015

[20] Master plan for Smart Sustainable cities, ITU FG-SSC, Technical Report. ITU 2015

[21] Reconceptualising Smart Cities: A Reference Framework for India, Center for Study of Science, Technology and Policy (CSTEP) September,
http://niti.gov.in/mgov_file/CSTEP\%

20Report\%20Smart\%20Cities\%20Fra mework.pdf

[22] Setting the framework for information and communication architecture of Smart Sustainable cities, ITU FG-SSC, Technical Report. ITU 2015

[23] Setting the stage for stakeholder' engagement in Smart Sustainable cities, ITU FG-SSC, Technical Report. ITU 2014

[24] Smart Cities, Mission Statement \& Guidelines, Government of India Ministry of Urban Development (June, 2015).

smartcities.gov.in/writereaddata/Smar tCity Guidelines.pdf

[25] Smart Cities, Project guide, Interreg IVB North Sea Region Programme, www.smartcities.info/files/Smart\%20 Cities\%20Project\%20Guide.pdf

[26] Smart Planning for a Smart City Infrastructure Modeling, Stuart Ravens, Jan 2012, OVUM http://twimgs.com/custom/agileinnova tion.techweb.com/assets/SmartPlannin gforSmarterInfrastruct ure.pdf

[27] Smart Sustainable cities a guide for city leaders, ITU FG-SSC, Technical Report. ITU 2015

[28] Smart Sustainable cities: an analysis of definitions, ITU FG-SSC, Technical Report. ITU 2014

[29] Standardization activities for Smart Sustainable cities, ITU FG-SSC, Technical Report. ITU 2015

[30] Standardization roadmap for Smart Sustainable cities, ITU FG-SSC, Technical Report. ITU 2015

[31] http://www03.ibm.com/press/us/en/pressrelease/2 7791.wss

[32] http://www.triplepundit.com/2012/03 /sustainable-cities-meeting-challengerapid-urbanization-focus-planetpressure-2012/

[33] http://smart-nrg.com/ 
Asia Pacific Journals

ISBN: 978-81-930411-5-4

Energy Ensemble (2015),

http://energyensemble.com/news_details.p

hp?news_id=240

http://saveonenergy.ca/Business/Program-

Overviews/Retrofit-for-Commercial.asp 